\title{
Emergences and affordances as opportunities to develop teachers' mathematical content knowledge
}

\author{
Cyril Julie
}

\begin{abstract}
Teachers' mathematical content knowledge has been under scrutiny for some time. This development is in the wake of learners' unsatisfactory performance in national examinations and international achievement tests. A widely held belief is that one, if not the most important, of the efforts to improve and enhance the performance and achievement in mathematics of learners is addressing teachers' mathematical content and pedagogical content knowledge through continuous professional development initiatives. The focus of this article is on the former. It describes how emergent and affording opportunities are brought to the fore from classroom observations and interactions in workshops and institutes with practising teachers. It concludes that this in situ dealing with mathematical content knowledge holds much promise for buy-in by teachers because it addresses an immediate need related to their practice.
\end{abstract}

\section{Introduction}

One of the reasons provided for schools graduating students with apparent insufficient command of mathematics to engage in mathematics at tertiary level is that the mathematical knowledge of their teachers is not strong. These sentiments are expressed in informal conversations I had with university lecturers of mathematics. More formally, this view is advanced during reviews of mathematics departments at higher education institutions in which I participated. Although not particularly targeted at the concerns of tertiary institutions, government departments also admit to the unsatisfactory achievement of learners in mathematics in national examinations. One of the first components in governments' strategies to address learners' unsatisfactory performance in high-stakes examinations is normally the enhancement of teachers' mathematical knowledge. For example, in their strategy for improving the quantity and quality of passes in mathematics in the final national examinations, one of the provincial departments of education in South Africa asserts that it will institute continuous professional development (CPD) initiatives focusing 'on subject content knowledge and skills as well as pedagogy'. $[1, p .9]$ The expected approach to proposals such as this is that practising teachers will be offered mathematical topic-specific in-service courses. Such courses are based on the school mathematics curricula and the topics will normally be those which analysis of school examination results rendered learners experienced difficulty with. Another strategy used for the identification of topics to be dealt with in these in-service mathematics offerings is those which tertiary institutions deem important for studies in mathematics in such institutions. For example, to address the assumed procedural approach to differentiation that dominates in the teaching of introductory calculus in schools in South Africa, it is the view of some mathematics departments that in-service courses in calculus 
based on the formal treatment of limits should be offered to practising mathematics teachers.

The enhancement of teachers' mathematical content knowledge is also a feature of many continuous professional development initiatives. In this article, I report on the development of mathematical awarenesses of teachers. These awarenesses originated from observations of classroom teaching and teachers' engagement in a continuous professional development initiative.

\section{Brief description of the continuous professional development initiative}

The project within which this research is embedded is the Local Evidence-Driven Improvement of Mathematics Teaching and Learning Initiative (LEDIMTALI). The project is underpinned by results and findings emanating from well-conceived systematic reviews of CPD projects. One systematic review yielded that continuous professional development initiatives for the improvement of mathematics teaching should be based on what teachers do in their classrooms and teachers should at the start be able to recognize that the CPD initiatives will have immediate applicability for their day-to-day classroom teaching.[2]

The overall purpose of the project is the development of teaching mathematics in the final 3 years of secondary schooling in South Africa. The project works with teachers from 10 schools to develop the teaching of mathematics. The demographic and other information of the participating teachers are given in Table 1 below.

In terms of mathematical content, the teachers with a 3-year college/university teaching qualification would as minimum have done differential calculus and the degree of some of those with a first degree and a teaching qualification would be in mathematics. Five university mathematics educators, one mathematician, two mathematics curriculum advisors and two general curriculum specialists form the research and development group, and are generally present and involved with all the activities with the teachers.

Table 1. Demographic information of participating teachers.

\begin{tabular}{|c|c|c|c|c|c|c|c|}
\hline Age & $n$ & $\begin{array}{c}\text { Teaching } \\
\text { qualification }\end{array}$ & $n$ & $\begin{array}{l}\text { Teaching } \\
\text { experience }\end{array}$ & $n$ & $\begin{array}{l}\text { Grades } \\
\text { taught }\end{array}$ & $n$ \\
\hline $20-25$ years & 2 & $\begin{array}{l}\text { 3-year college/university } \\
\text { teaching qualification }\end{array}$ & 8 & $0-5$ years & 4 & 10 & 14 \\
\hline 26-30 years & 0 & $\begin{array}{l}\text { 4-year college/university } \\
\text { teaching qualification }\end{array}$ & 4 & $6-10$ years & 3 & 11 & 10 \\
\hline $31-35$ years & 7 & B Ed degree & 2 & $11-15$ years & 1 & 12 & 12 \\
\hline $36-40$ years & 1 & $\begin{array}{c}\text { First degree }+ \text { teaching } \\
\text { qualification }\end{array}$ & 10 & $16-20$ years & 7 & & \\
\hline $41-45$ years & 4 & $\begin{array}{l}\text { Postgraduate degree }+ \\
\text { teaching qualification }\end{array}$ & 2 & $21-25$ years & 5 & & \\
\hline $46-50$ years & 7 & & & More than 25 years & 5 & & \\
\hline $51-55$ years & 3 & & & & & & \\
\hline Over 55 & 2 & & & & & & \\
\hline
\end{tabular}




\section{Teachers' 'informal' learning of mathematics}

Practising teachers learn mathematics in a variety of situations. The most common form of exposing teachers to learn mathematics is formal in-service courses dealing in a disciplinary-structured way with the content of mathematics. Opportunities for learning the content also occur in non-formal situations. This kind of learning mathematics is referred to as 'incidental learning'.[3] A feature of this kind of learning of mathematical content is that during teaching through incidences such as a question from a learner or a prompt from a peer or other knowledgeable person, opportunities arise for teachers to reflect on mathematical content either individually or collectively. This leads to teacher 'acquiring a "better" understanding of what is being taught'.[4,p.ix]

Zazkis and Mamolo researched teachers' mathematics at the horizon described as 'teachers' mathematical knowledge beyond the school curriculum'.[5,p.8] Their objective was to identify how the knowledge teachers acquired during their training came to the fore and is being used during teaching. In particular, they focus on how teachers drew on this higher level mathematical knowledge to make decisions to respond to learners' ways of working with mathematical activities.

Rowland [6] relates how an opportunity arose spontaneously to deal with a prospective teacher's mathematical knowledge. She posed him a question during her working on tasks on tangrams and pentominoes. She wanted to know from him whether he knew the relationship between the volume of a cone and cylinder with the same base and height. He considered various derivations as explanations for the relationship and ended providing her with what 'amounted to an instructional explanation'.[6,p.10] Rowland and his colleagues also developed a framework for analysing teacher's knowledge, the knowledge quartet.[7] It comprises 'four broad, superordinate categories or "units", which we have named (1) foundation, (2) transformation, (3) connection and (4) contingency'.[7,p.110] Of particular interest for this article is that the contingency element of the 'knowledge quartet' is focused on. This component is described as the ability of teachers to "think on [their] feet" and respond appropriately to the contributions made by [their] students during a teaching episode'.[8,p.266]

Further reference to the change in a teacher's knowledge of mathematics is, for example, made when a teacher engaged with tasks related to the factorization of $x^{n}-1$. The teacher's engagement with researchers designing tasks related to the aforementioned issue resulted in '... new mathematical awarenesses, which thereby constituted a first round of change with respect to [the teacher's] existing mathematical knowledge'.[9,p.144-145]

The emphasis of the research reported in this article focuses on whether or not teachers do have this higher level mathematical knowledge at hand during their teaching or in designing mathematical tasks.

\section{Data collection}

The major data collection sites of importance for this article were mathematics classrooms, workshops and immersion teacher institutes. During 2012, 4 visits were made to each of the 10 schools to observe the teaching of mathematics. Teachers were informed not to prepare 
special lessons nor were they to deem these visits as inspections. The author led all the visits and was at times accompanied by project colleagues or a curriculum advisor.

Some teachers expressed trepidation with being video-recorded whilst teaching and hence only observation notes were taken.

Observation notes were handwritten, typed and cleaned normally not longer than a day after the lesson was observed. The typed lesson notes were forwarded to the teacher for checking accuracy, addition of issues he/she thought was left out and deletion of issues he/she felt uncomfortable with.

Workshops were held after school and normally lasted about 2 hours. Six workshops were held in 2012. The contents of the workshops generally focused on issues related to teaching mathematics and dilemmas that teachers experience within the teaching context they find themselves.

Teacher institutes are of 2-3 days' duration and participants stay together and overnight at the same venue for the entire period. These institutes allow for more concentrated and extended work on topics related to the teaching of mathematics. Topics dealt with, for example, were analysis of mathematics lessons, planning teaching and learning environments, fostering a culture of studying mathematics by learners, aligning teaching with learning, using errors and misconceptions emerging from learners' work in examinations in teaching, setting and marking final school-based examinations and evaluating teaching scripts. Teachers are also engaged in doing some mathematics related to the prescribed curriculum. This is done to develop the mathematicalness [10] of the teachers. For example, teachers were given the problem: 'Given a line segment AB. Choose a point $\mathrm{C}$ on $\mathrm{AB}$ and draw two equilateral triangles $\mathrm{ACD}$ and $\mathrm{CBE}$ on the same side of $\mathrm{AB}$. Compare the lengths of the line segments $\mathrm{AE}$ and $\mathrm{BD}$ when $\mathrm{C}$ varies along $\mathrm{AB}$ ', and they had to use different ways of approaching the problem.

The video recordings, observation notes and the newsprint feedback to activities of the workshops and institutes are the sources of data used.

In addition to these data sources, teachers completed an evaluation questionnaire during the last workshop of the year. One of the items was related to pieces of mathematics dealt with spontaneously in the workshops and institutes. They had to indicate whether the pieces of knowledge were known or not to them before being exposed to the piece of mathematics in the project. These pieces of knowledge are focused on this article.

\section{Data analysis}

The research and development group, mentioned above, scrutinized the collected data to identify incidences where teacher's mathematical knowledge was ostensibly enhanced. From the observation notes, the selection was based on whether opportunities to respond to contributions of learners' were not capitalized on and the research and development group's judgement and experience on whether it is a reasonably widespread occurrence. This selection occurs through competitive argumentation in the research and development group meetings and is driven by the quest to identify 'opportunities to enhance [teachers' 
mathematical] knowledge...'.[7,p.257] The handling of mathematics during workshops and institutes is identified from the videos by its spontaneous occurrence and on-the-spot suspension from whatever endeavour, other than specific mathematics, was the focus of activity.

I classify these incidental learning opportunities as either an emergence or an affordance. These constructs are not a framework for analysing teaching per sé. They are descriptors, based on their site of origin, for identifying mathematical knowledge elements to be clarified to teachers.

In the next two sections, these processes of identification of higher level mathematical knowledge are described and exemplified.

\section{Emergence}

An emergence is an opportunity which arises during teaching. It might be a mathematical question raised by a learner and the teacher does not have a readily available response at hand and hence has to seek for a satisfactory response to the learners' query. Or, it might be an error or misconception that is forthcoming from responses from learners and the teacher does not attend to them. Emergences thus surface in classrooms during teaching. In $[7,8]$, incidences are relayed where two prospective mathematics teachers did not respond to their learners' contributions. An emergence is the identification of such non-exploitation of learner contributions particularly with respect to errors and misconceptions learners display.

One emergent opportunity arose. This occurred in a geometry lesson. A learner was recording his solution on the chalkboard. Part of the problem the teacher dealt with is given in Figure 1.

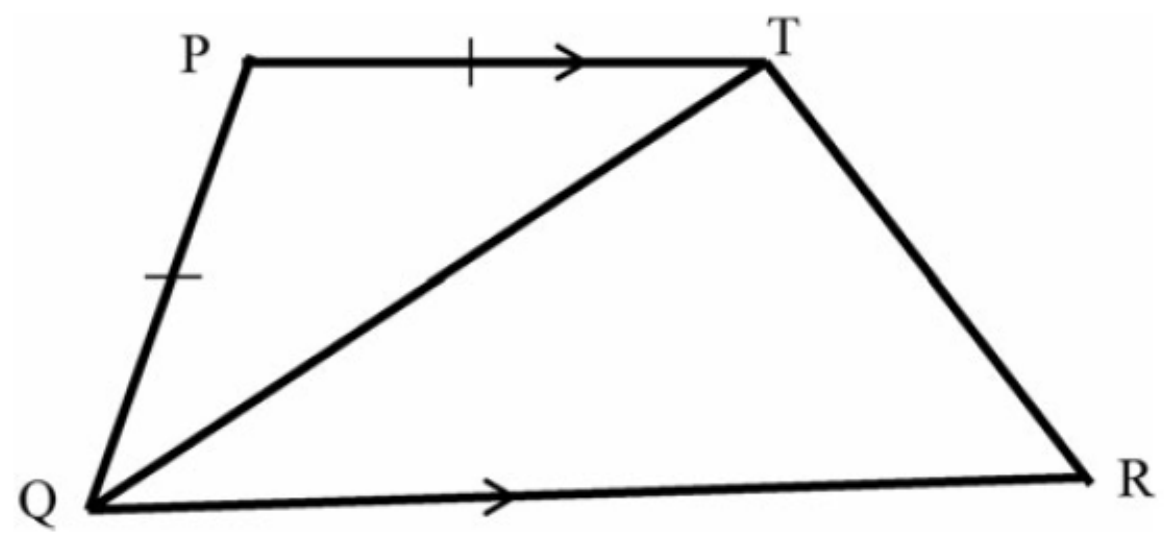

The problem dealt with was in quadrilateral PQRT, PT\|QR, PT $=\mathrm{PQ}, \angle \mathrm{TQR}=2 x$ and $\angle \mathrm{QTR}=90^{\circ}-x$. Find the value of $\angle \mathrm{P}$ in terms of $x$.

The learner gave the reason for $\angle \mathrm{Q}=\angle \mathrm{T}_{1}=2 x$ as being 'alternate angles'. The teacher did not attend to this common mistake learners make when they work with problems related to 
angles and parallel lines. The teacher was informed during the post-lesson discussion of this non-attendance.

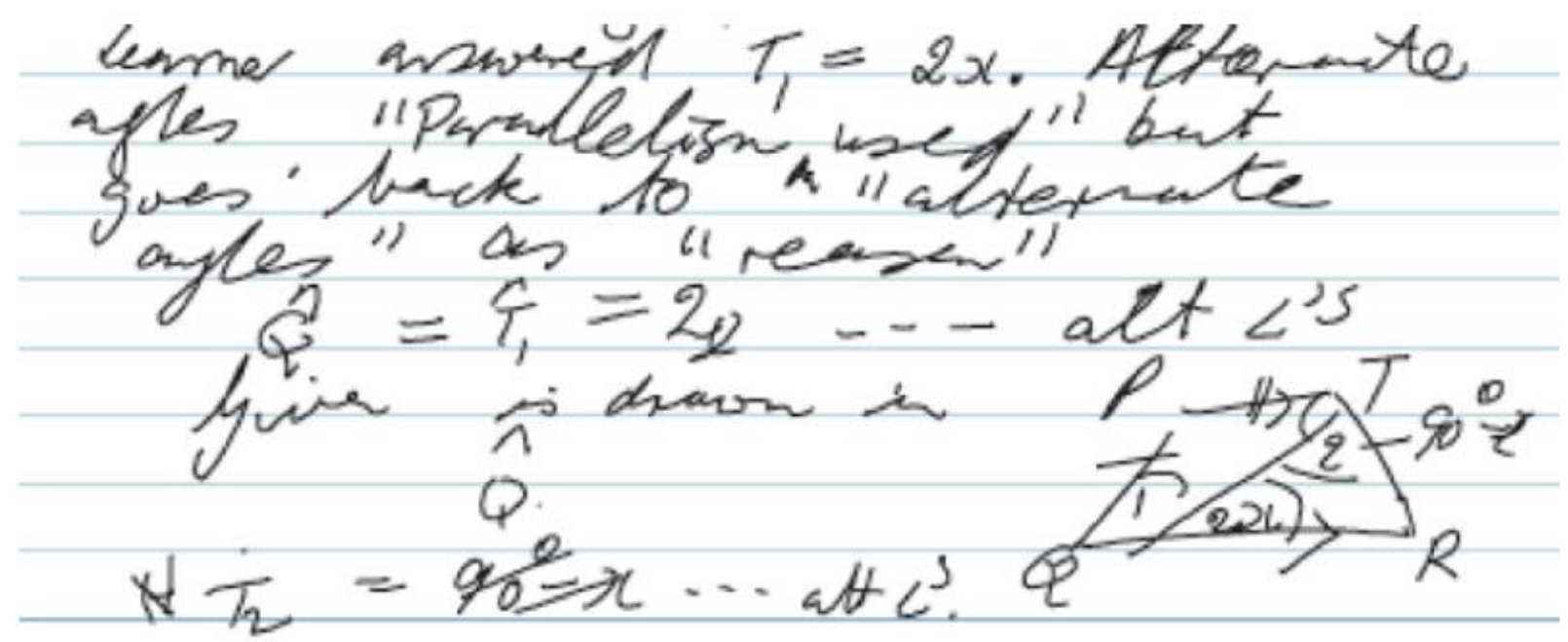

Figure 1. Excerpt of handwritten notes depicting an 'error'.

During a subsequent classroom visit to another school, a similar phenomenon was observed for another problem related to angles and parallel lines on the chalkboard for a worked-out problem, the same reason was written for the equality of angles. The reason for learners using the type of angle as the reason for the equality of angles might be linked to these angle types only being taught in conjunction with parallelism.

The essence of the workshop handling of the topic was linking it to Euclid's fifth postulate and informing the participants that this is normally the postulate on which the construct of parallelism is based. Sixteen of the 21 teachers who responded indicated that Euclid's fifth postulate was not known to them before encountering it in the project.

\section{Affordance}

An affordance is a situation where teachers engage with activities related to mathematics teaching and other participants direct the focus to a discussion on mathematical content. Thus different to emergences they do not arise during the teaching of mathematics. They are initiated by mathematical activities at hand, are normally mathematically related questions raised by participants and are dealt at the moment of their surfacing.

The description of teachers' experiences is not the focus of this article. During the workshops and institutes, they were not teaching as is the case of the teachers referred to by.[5] Rather the focus is on the mathematical knowledge elements which teachers themselves indicated were 'not known' to them before encountering them in the instances provided.

Overall seven affording opportunities arose. Three of these are presented based on the lowest, the highest and about half of the respondents indicating that the pieces of mathematics were not known to them before. Also, they surfaced during sessions dealing with the construction and marking of an end-of-year final examination in which eight of the participating schools agreed to write. The entire project cohort participated in the setting of the examination and the teachers marked their own schools' scripts. In order to 
ensure consistency of marking a session in a teacher institute was devoted to discuss the memorandum of marking. Teachers were requested to bring to the institute some of the scripts they had already marked.

The lowest percentage (33.3\%) of teachers responded that they did not know that factorization in school mathematics is restricted to factorization over the rational numbers. The affording opportunity resulted from discussing the marking of the question 'Factorise $x^{3}-x^{2}-5 x+5$ '. One participant wanted to know if the offered answer $\left(x^{2}-5\right)(x-1)$ is the fully factorized form of the expression. This led to whether $x^{2}-5$ should be further factorized. By resorting to the occurrences of factorization in the operative curriculum, textbook presentations and previous examinations, it was settled that factorization of polynomial expressions in grade 10 is restricted over the rational numbers. As can be observed, the resolution of this question was based on curriculum policy documents and the interpretation of such documents as manifested in textbooks and examinations. The resolution was not a disciplinary explanation. The disciplinary explanation resides in abstract algebra. It uses the idea of integral domains, fields and the division algorithm for polynomials. Briefly, with $P[x]$ as the set of all single-variable polynomials in a variable $x$ with the coefficients in the domain of integer $(Z[x])$, rational $(Q[x])$, real $(R[x])$ or complex $(C[x])$ numbers, the system $(P[x],+, \bullet)$ with + and $\bullet$, two binary operations, is an integral field. For $(Q[x],+$, -), the integral domain of polynomials with rational coefficients, polynomials with irrational coefficients are not allowable. In particular for the factorization under discussion, the two factors of $x^{2}-5$ are $x-\sqrt{ } 5$ and $x+\sqrt{ } 5$. The two factors, however, are binomials with the $x^{\mathrm{O}}$ terms having irrational coefficients and hence flouting the condition that the all coefficients must be rational. The workshop facilitators did not capitalize to make the participating teachers aware of this disciplinary explanation. This might be due to most mathematics teachers in South Africa not dealing with abstract algebra during their pre-service education. Consequently, the conventionality of the factorization over the set of rational numbers was deemed as adequate. However, the occurrence of the issue of 'fully factorized' in this context gives a pointer to a disciplinary explanation for inclusion in more formal continuous professional development courses aimed at enhancing teachers' mathematics subject matter knowledge.

Sixteen teachers indicated that they could not prove that $2+\sqrt{ } 3$ is an irrational number before encountering it in the project. This affordance also surfaced during a teacher institute where the marking of the common end-of-year examination was discussed. The question at stake was 'Consider the expression $\sqrt{ } \frac{12}{x+1}$ and write down one value of $x$ that will make the expression an irrational rational number.' One of the participants posed the question 'How can we prove that $2+\sqrt{ } 3$ is irrational?' This led to the discussion of a proof as presented in Figure 2. 


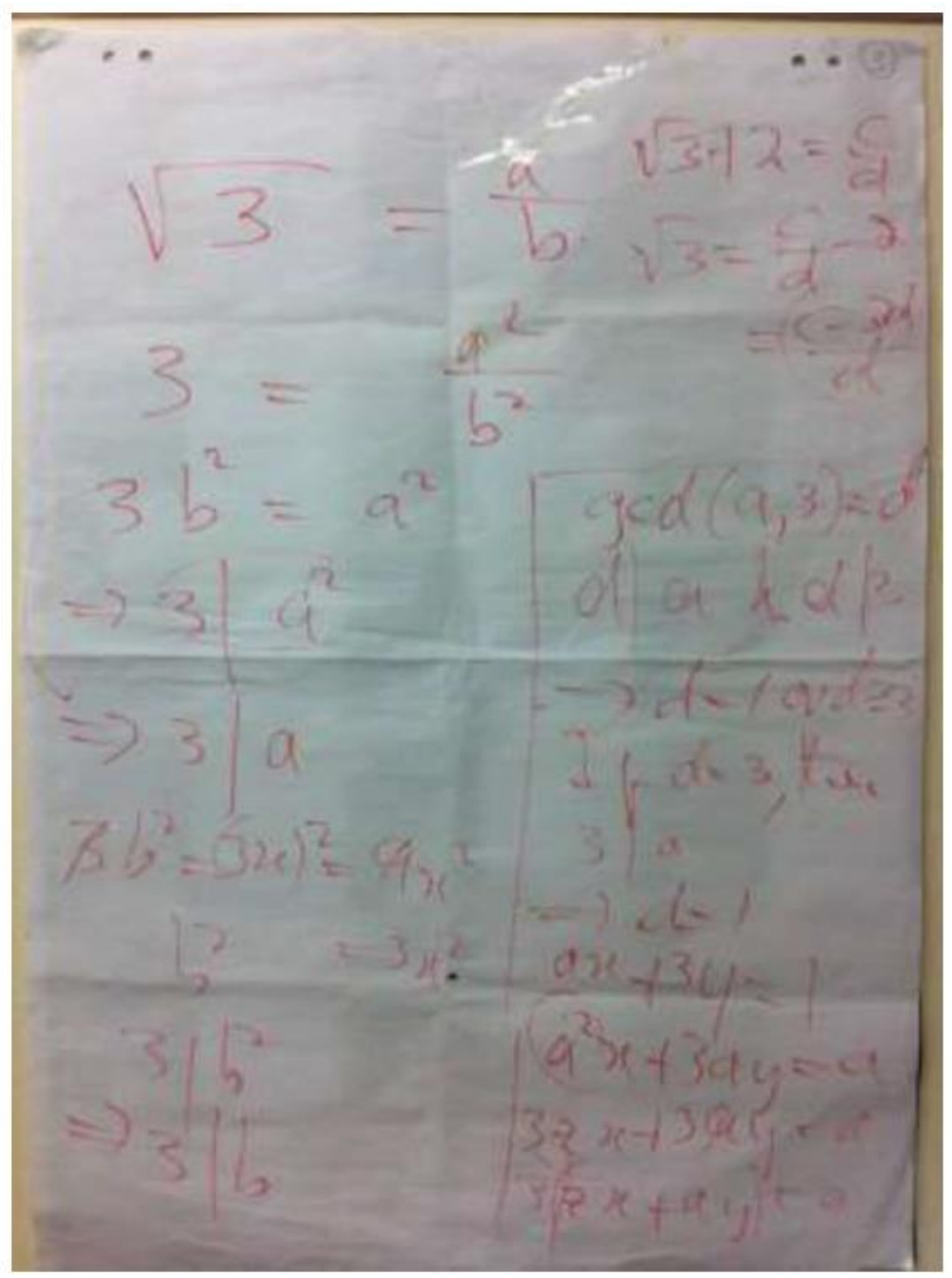

Figure 2. Proof of irrationality of numbers.

In a follow-up workshop, teachers were provided with notes on a proof that $\sqrt{ } 3$ is irrational. It also appears that teachers felt that learners in grade 10 can deal with such proofs. In a session dealing with the preparation of work for the 2013 school year, they planned to deal with the proof at the problem-solving knowledge level when they will deal with the topic, the real number system.

The presentation of the proof, as can be discerned from Figure 2 and the notes provided to the teachers, was the normal indirect one. In its presentation, the Fundamental Theorem of Arithmetic and the idea of 'relatively prime', underlying the proof, were not referred to.

In a sense the presenter could get 'away' without it because the proof also was not general by focusing on the particular, in this case, $\sqrt{ } 3$. As was the case with the previous example, seeds for extending teachers' mathematical subject knowledge are discernible from this instance. 
During the construction of the examination paper, a participant offered 'Is $2 \sin \varnothing=$ $\sin 2 \varnothing$ true?' as a question for inclusion in the examination. Two marks were awarded for this question and the proposed answer was given as 'false'. The proposer justified the inclusion of the item as follows:

In my experience in the later grades when I do the solution of trigonometric equations after dealing with double angle formulae, some learners would simplify sin $2 \varnothing$ to $2 \sin \varnothing$. I use special angles 30, 45 and 60 degrees to show them that they cannot just take the 2 to the front. This shows them that $\sin 2 \varnothing \mathrm{I}=2 \sin \varnothing$.

This led to a discussion on whether $2 \sin \varnothing=\sin 2 \varnothing$ is always false and the extension that mathematical statements can be 'always, sometimes and never' [11] true. It was resolved that $2 \sin \varnothing=\sin 2 \varnothing$ is sometimes true. Twelve of the 21 responding teachers reported that this was new knowledge to them.

\section{Discussion}

The incidences reported above show that opportunities for enhancing and extending the mathematical content knowledge of practising teachers surface at varying sites and under varying conditions. A sometimes knee-jerk reaction to deal with the supposed unsatisfactory knowledge of teachers is, as alluded to above, that they should be offered structured courses in mathematics. A worst-case scenario of this approach is that courses be locked into the school curriculum' as was found in a review of formal in-service courses to deal with teachers' mathematical knowledge in South Africa.[12] Although there is much for teachers to benefit from such courses, it runs the risk of mistargeting what teachers' needs are in terms of extending their mathematical knowledge to deal with the mathematics in classrooms.

Another approach to get a sense of the mathematical knowledge needs of teachers is through testing embedded in the mathematical knowledge for teaching paradigm which is described as '.. .not only.. .common [mathematical] content knowledge but also...specialized knowledge for teaching mathematics'.[13] This paradigm is driven by learners' ways of engagement with mathematics as the pivot around which teachers' content knowledge is assessed. Some items in the tests from this paradigm are of a pure content nature. Others are embedded in the pedagogical content knowledge perspective where the test items are scenario-based situations of learners' work to which teachers must respond. An example from [13] suffices.

Ms Harris was working with her class on divisibility rules. She told her class that a number is divisible by 4 if and only if the last two digits of the number are divisible by 4 . One of her students asked her why the rule for 4 worked. She asked other student if they could come up with a reason. Which of the following statements comes closest to explaining the reason for the divisibility rule for 4 ? (Mark ONE answer.)

1. Four is an even number, and odd numbers are not divisible by even numbers.

2. The number 100 is divisible by 4 (and also 1000, 10,000, etc.).

3. Every other even number is divisible by 4 , for example, 24 and 28 but not 26 .

4. It only works when the sum of the last two digits is an even number.

$$
\text { http://repository.uwc.ac.za }
$$


This approach has value in terms of determining the guiding focus of enhancing teachers' knowledge with a strong emphasis of directing attention to mathematically deal with peculiarities exhibited by the work of learners in classrooms. It can be deemed similar to elementary mathematics from an advanced perspective but the advanced perspective is mathematics education, not mathematics.

The work reported here has some similarity with the last approach but it does not subject teachers to tests. Rather, content is identified from authentic classroom and other situations from their spontaneous surfacing when participants are engaged in activities of immediate relevance to the entire mathematics teaching enterprise. In dealing with the content, an advanced mathematical lens is cast over it to enhance the teachers' content knowledge. Thus, the stance taken is strongly influenced by Klein's perspective of elementary mathematics from an advanced mathematical point of view and the notion of mathematics at the horizon.[5]

\section{Conclusion}

There is a widespread agreement that the issue of teacher mathematics content is complex. A memorandum to the British parliament captures the complexity as 'There is no simple relationship between qualifications and teaching effectiveness - some less mathematically qualified and/or less well-trained people who are intelligent, reflective and resourceful can develop considerable expertise, whereas some teachers with maths PhDs and a full PGCE fail to progress beyond adequate'.[14] I contend that more attention, than is currently the case, should be accorded to emergent and affording opportunities to deal with the enhancement of teachers' mathematical knowledge. This would require much 'dirtying of boots' in classrooms to identify emergent opportunities in situ. It also needs an alertness and sensitivity to recognize affording opportunities when working with teachers in continuous professional development settings on tasks and activities related to their day-to-day practice. The near-immediate dealing with mathematical content from such emergent and affording opportunities holds the potential of greater buy-in by teachers since it has power of convincing teachers that it 'really has to do with what we are doing'.

The downside is that mathematics is dealt within a piecemeal manner and that structure is lost. However, a collection of the pieces of mathematics might, over a period of time, render sufficient constituting elements which can be structurally arranged without losing the flavour of being immediately relevant and recognized as such by mathematics teachers.

\section{Acknowledgements}

Any opinions, findings and conclusions or recommendations expressed in this material are those of the author and do not necessarily reflect the views of the National Research Foundation.

\section{Funding}

This research is supported by the National Research Foundation [grant number 77941]. 


\section{References}

[1] Western Cape Education Department. Strategy for mathematics and physical science for grades 8-12: 2012-2015. Cape Town: WCED; 2012.

[2] Cordingley P, Bell M, Rundell B, Evans D. The impact of collaborative CPD on classroom teaching and learning, version 1.1. London (UK): Research Evidence in Education Library, EPPI-Centre, Social Science Research Unit, Institute of Education; 2003.

[3] Perrin-Glorian M-J, DeBlois L, Robert A. Individual practicing mathematics teachers: studies on their professional growth. In: Wood $\mathrm{T}$, Krainer $\mathrm{K}$, editors. International handbook of mathematics teacher education. Vol. 3, Participants in mathematics teacher education: individuals, teams, communities, and networks. Rotterdam: Sense Publishers; 2008. p. 35-59.

[4] Leikin R, Zazkis R. Learning through teaching mathematics : development of teachers' knowledge and expertise in practice. Vol. 5. Dordrecht: Springer; 2010.

[5] Zazkis R, Mamolo A. Reconceptualizing knowledge at the mathematical horizon. Learn Math. 2011;31(2):8-13.

[6] Rowland T. Explaining explaining. In: Nieuwoudt S, Laubser D, Dreyer H, editors. Proceedings of the 18th annual national congress of the Association for Mathematics Education of South Africa. Potchefstroom (South Africa): Northwest University; 2012. p. $1-13$.

[7] Rowland T, Turner F. Developing and using the 'Knowledge Quartet': a framework for the observation of mathematics teaching. Math Educ. 2007;10(1):107-124.

[8] Rowland T, Huckstep P, Thwaites A. Elementary teachers' mathematics subject knowledge: the knowledge quartet and the case of Naomi. J Math Teach Educ. 2005;8(3):255-281.

[9] Kieran C, Guzmá n J. Role of task and technology in provoking teacher change: a case of proofs and proving in high school algebra. In: Leikin R, Zazkis R, editors. Learning through teaching mathematics : development of teachers' knowledge and expertise in practice. Vol. 5. Dordrecht: Springer; 2010. p. 127-152.

[10] Mason J, Davis J. Fostering and sustaining mathematics thinking through problem solving. Geelong: Deakin University; 1991.

[11] Watson A, Mason J. Questions and prompts for mathematical thinking. Derby: Association of Teachers of Mathematics; 1998.

[12] Council for Higher Education. Report on the national review of academic and professional programmes in education. Pretoria (South Africa): CHE; 2010. (HE Monitor No. 11).

[13] Hill HC, Loewenberg Ball D. Learning mathematics for teaching: results from California's mathematics professional development institutes. $J$ Res Math Educ. 2004;35(5):330-351.

[14] Brown M. Some points relating to the teaching of mathematics. 2010. Available from:

http://www.publications.parliament.uk/pa/cm200910/cmselect/cmchilsch/340/100210 02.htm 